\title{
The association between borderline personality disorder, fibromyalgia and chronic fatigue syndrome: systematic review
}

\author{
Sarah Penfold, Emily St. Denis and Mir Nadeem Mazhar
}

\section{Background}

Overlap of aetiological factors and demographic characteristics with clinical observations of comorbidity has been documented in fibromyalgia syndrome, chronic fatigue syndrome (CFS) and borderline personality disorder (BPD).

\section{Aims \\ The purpose of this study was to assess the association of BPD with fibromyalgia syndrome and CFS. The authors reviewed literature on the prevalence of BPD in patients with fibromyalgia or CFS and vice versa. \\ Methods \\ A search of five databases yielded six eligible studies. A hand search and contact with experts yielded two additional studies. We extracted information pertaining to study setting and design, demographic information, diagnostic criteria and prevalence.}

\section{Results}

We did not identify any studies that specifically assessed the prevalence of fibromyalgia or CFS in patients with BPD. Three studies assessed the prevalence of BPD in fibromyalgia patients and reported prevalence of 1.0, 5.25 and $16.7 \%$. Five studies assessed BPD in CFS patients and reported prevalence of $3.03,1.8,2.0,6.5$ and $17 \%$.

\section{Conclusions}

More research is required to clarify possible associations between BPD, fibromyalgia and CFS.

\section{Declaration of interest}

None.

\section{Copyright and usage}

(c) The Royal College of Psychiatrists 2016. This is an open access article distributed under the terms of the Creative Commons Non-Commercial, No Derivatives (CC BY-NC-ND) license.
Borderline personality disorder (BPD) is a psychiatric disorder characterised by pervasive instability in affect regulation, impulse control, interpersonal relationships and self-image. It is associated with severe psychological impairment and a high risk of suicide. ${ }^{1}$ The prevalence of BPD is estimated to be $1-2 \%$ in the general population, with a female to male ratio of $3: 1 .^{2-4}$ While childhood sexual abuse is neither necessary nor sufficient for development of BPD, $40-71 \%$ of patients with BPD report a history of childhood sexual abuse. ${ }^{1}$ Heritability of the disorder is estimated to be $47 \% .{ }^{1}$ Neurobiologically, there is evidence that individuals with BPD have altered functioning in multiple regions of the brain including the anterior cingulate gyrus, hippocampus, amygdala and orbitofrontal cortex, as such BPD is conceptualised as decreased prefrontal inhibitory control and amygdala hyperactivity. ${ }^{1}$ It has been shown that individuals with BPD access health resources more than those with other psychiatric disorders. ${ }^{5}$

Fibromyalgia is a syndrome characterised by widespread pain, abnormal pain processing, sleep disturbance, fatigue and psychological distress. ${ }^{6,7}$ The aetiology of fibromyalgia remains unknown; however, there are often characteristic alterations in sleep pattern and changes in neuroendocrine transmitters such as serotonin, substance $\mathrm{P}$, growth hormone and cortisol that suggest that the pathophysiology of the syndrome may be associated with autonomic and neuroendocrine regulation. ${ }^{8}$ Central sensitisation, dampening of inhibitory pain pathways and changes in neurotransmitters can lead to abnormal processing of sensory signals in the central nervous system, as such lowering the pain threshold and amplifying sensory signals causing constant pain. ${ }^{8}$ Frequent comorbidity of fibromyalgia and mood disorders suggests a role for the stress response and for neuroendocrine abnormalities in the disease process. ${ }^{8}$ The hypothalamic pituitary axis (HPA) is a critical component of the stress-adaptation response. In fibromyalgia, the stress-adaptation response is disrupted, leading to stress-induced symptoms. ${ }^{8}$ Patients with fibromyalgia also often suffer from comorbid anxiety disorders. ${ }^{9}$ They are also more likely to have histories of early-life physical or sexual abuse, neglect, family history of alcohol-use disorder and post-traumatic stress disorder (PTSD). ${ }^{10}$ Furthermore, personality has been suggested as an important factor in modulating a person's response to psychological stressors, and certain personalities may facilitate translation of these stressors to symptoms characteristic of fibromyalgia. ${ }^{11}$ The prevalence of fibromyalgia in the general population is approximately $2 \%$, with women affected 10 times more than men. ${ }^{12}$

Chronic fatigue syndrome (CFS) is a condition characterised by 6 months or more of persisting or relapsing fatigue. The fatigue is not relieved by rest, nor explained by medical or psychiatric conditions, and it is accompanied by a range of cognitive and somatic symptoms. ${ }^{13}$ The pathophysiology of CFS remains unclear. However, research continues to point towards central nervous system involvement. ${ }^{14}$ A hyperserotonergic state and hypoactivity of the HPA have also been indicated, but it remains uncertain whether these are a cause of or consequence of CFS. ${ }^{14}$ Female gender genetic disposition, certain personality traits and physical and emotional stressors have been identified as risk factors. ${ }^{15,16}$ Moreover, exposure to childhood trauma has been found to increase the risk of CFS three- to eightfold. ${ }^{17}$ Prevalence of CFS in primary care setting ranges from 3 to $20 \%{ }^{18,19}$

Comorbidity of BPD and fibromyalgia has been postulated. The disorders share common aetiological factors such as childhood trauma and preponderance in females, and they are observed to cooccur with similar psychiatric conditions such as depression, anxiety disorders and PTSD. ${ }^{20}$ There is also considerable clinical overlap between fibromyalgia and CFS. One study found that $21.2 \%$ of patients diagnosed with fibromyalgia also met criteria for CFS. ${ }^{20}$

Though the core features of fibromyalgia, CFS and BPD differ (pain $v$. fatigue $v$. emotional dysregulation), the overlap in 
aetiological factors and demographic characteristics in addition to our clinical observations of comorbidity compelled us to explore possible relationships between the disorders of interest. Our aim was to determine whether patients with fibromyalgia or CFS are more likely to suffer from BPD - and conversely, are patients with BPD more likely to suffer from fibromyalgia and CFS? We hypothesised that, since patients with BPD experience significant chronic stress related to interpersonal difficulties and emotional dysregulation, they would be more likely to suffer from CFS and/or fibromyalgia, two disorders which are believed to be related to maladaptive stress responses. If our hypothesis turned out to be true, those with BPD would be over-represented among samples of patients suffering from fibromyalgia or CFS.

\section{Method}

\section{Data sources and terms used}

A literature search was conducted of EMBASE, Medline, PsycINFO, CINAHL and Cochrane Systematic Reviews databases for eligible studies. Search terms included fibromyalgia, CFS, personality disorder, Axis II, emotionally unstable personality disorder and BPD. Emotionally unstable personality disorder was included as a search term because it is the ICD-10 equivalent of BPD. The search included studies from 1 January 1990 - the year the American College of Rheumatology (ACR) published diagnostic criteria for fibromyalgia - to 7 July 2015.

\section{Study selection}

Studies fulfilling the following criteria were included in this review: (1) examined the prevalence of fibromyalgia and/or CFS in patients with $\mathrm{BPD}$, or examined prevalence of $\mathrm{BPD}$ in patients with fibromyalgia and/or CFS; (2) used valid criteria for diagnosis; (3) published in a peer-reviewed journal; 4) published in English or French.

The inclusion criteria were developed by the supervising author and reviewed by the co-authors.

\section{Data extraction}

The following data were extracted from each study: country of study, publication year, number of participants, study setting (in-patient, out-patient/community), study design, gender distribution, mean age or age range of the participants, diagnostic criteria applied for BPD, fibromyalgia and CFS, and prevalence. The supervising author conducted data extraction. A meta-analysis could not be conducted due to heterogeneous characteristics of selected studies.

\section{Results}

The EMBASE, Medline, PsycInfo, CINAHL and Cochrane Systematic Reviews database searches identified 27, 13, 13, 3 and 0 studies, respectively. Study titles and abstracts were reviewed independently by all three co-authors, and 15 studies were identified as potentially relevant. These studies were reviewed in full by the supervising author, and nine were excluded, as they did not meet the inclusion criteria. Six studies were found to be eligible for analysis in the systemic review. It was agreed that supervising author's decision would prevail in case of any potential disagreements. The supervising author subsequently conducted a hand search of the references of the six eligible studies, identifying one additional relevant study. An additional study was included after contact with an expert in the field (Fig. 1).

Table 1 lists the characteristics of studies assessing the prevalence of BPD in patients with fibromyalgia. All three studies used the ACR criteria for the diagnosis of fibromyalgia and the Structured Clinical Interview for DSM-III Personality Disorders (SCID-II). The 2004 study by Thieme et al evaluated the prevalence and predictors of psychiatric disorders in 115 women with fibromyalgia, and the authors found that $5.25 \%$ of participants met criteria for BPD. ${ }^{21}$ The 2009 study by Rose et al investigated the prevalence of Axis 1 and Axis II disorders among 30 patients with fibromyalgia referred to consultation psychiatry as a facet of treatment within a specialised pain consultation service. There, $16.7 \%$ of the patients met criteria for BPD. ${ }^{22}$ The 2010 study by Uguz et al examined the prevalence of Axis I and Axis II psychiatric disorders in 103 patients with fibromyalgia as compared with

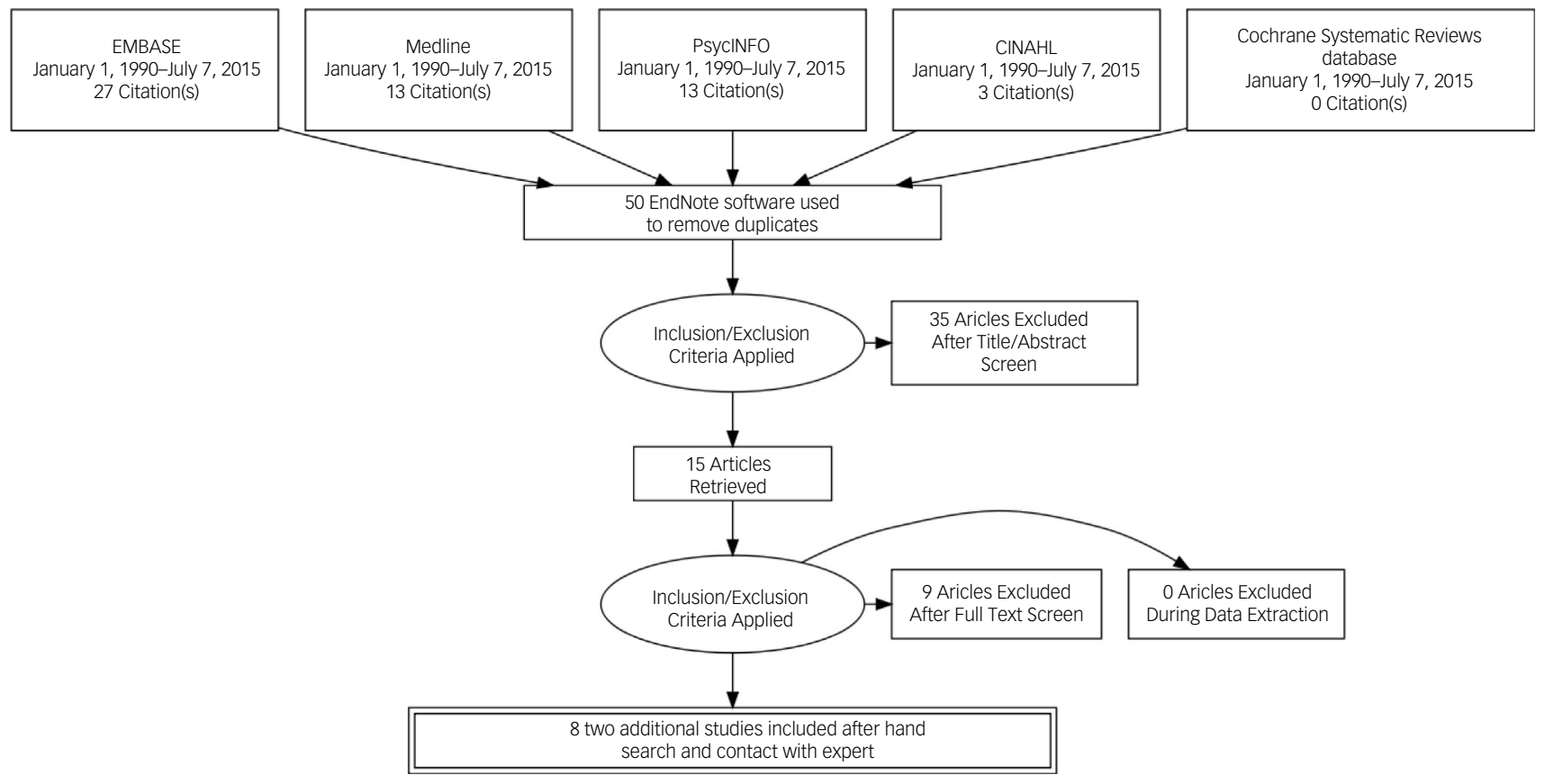

Fig. 1. Literature search strategy 


\begin{tabular}{|c|c|c|c|c|c|c|c|c|}
\hline Authors & $\begin{array}{l}\text { Country } \\
\text { of study }\end{array}$ & $\begin{array}{c}\text { Year } \\
\text { published }\end{array}$ & $\begin{array}{l}\text { Participants with } \\
\text { fibromyalgia }(n)\end{array}$ & $\begin{array}{c}\text { Study } \\
\text { setting/design }\end{array}$ & $\begin{array}{c}\text { Diagnostic } \\
\text { criteria }\end{array}$ & Sex & Age (s.d.) & $\begin{array}{l}\text { Prevalence } \\
\text { of BPD (\%) }\end{array}$ \\
\hline Thieme et $a l^{21}$ & Germany & 2004 & 115 & Out-patient/case series & $\begin{array}{l}\mathrm{SCID}-\|^{*} \\
\mathrm{ACR}^{* *}\end{array}$ & $100 \%$ female & $\begin{array}{c}48.17 \\
(10.32)\end{array}$ & 5.25 \\
\hline Rose et $\left.a\right|^{22}$ & France & 2009 & 30 & Out-patient/case series & $\begin{array}{l}\text { SCID-I* } \\
\text { MINI }^{\dagger} \\
\text { ACR }^{* *}\end{array}$ & $73 \%$ female & $\begin{array}{l}48.4 \\
(9.5)\end{array}$ & 16.7 \\
\hline Uguz et $a 2^{23}$ & Turkey & 2010 & 103 & Out-patient/case control & $\begin{array}{l}\text { SCID-II* } \\
\mathrm{ACR}^{* *}\end{array}$ & $100 \%$ female & Not given & 1 \\
\hline
\end{tabular}

sociodemographically matched controls. ${ }^{23}$ The prevalence of BPD was $1 \%$ in patients with fibromyalgia and $0 \%$ in control individuals, a non-statistically significant difference. ${ }^{23}$

Table 2 lists the characteristics of studies assessing the prevalence of BPD in patients with CFS. Five studies were identified. All of the studies used the Centers for Disease Control (CDC) criteria for CFS and relied on self-report questionnaires such as the Personality Diagnostic Questionnaire-Revised or 4th edition (PDQ-R, PDQ-IV) or the Assessment of DSM-IV Personality Disorders Questionnaire (ADP-IV) for diagnosis of personality disorders. The 1996 study by Johnson et al investigated the relative rates of personality disorders in patients with CFS, compared with patients with multiple sclerosis, control patients with depression and healthy controls. ${ }^{24}$ The prevalence of BPD was found to be $17 \%$ in those with CFS, $25 \%$ in patients with multiple sclerosis, $29 \%$ in control patients with depression and $0 \%$ in healthy controls. ${ }^{24}$ The 2009 study by Courjaret et al assessed the prevalence of personality disorders in a sample of female CFS patients compared with two control groups (psychiatric and general population controls). ${ }^{25}$ The study found that the prevalence of BPD was 2, 42 and $6 \%$ in the CFS, psychiatric and general population groups, respectively. ${ }^{25}$ The 2010 population-based study by Nater et al compared the prevalence of personality disorders and traits of survey respondents meeting criteria for CFS versus respondents with 'insufficient fatigue' and 'well' respondents. The authors found that the prevalence of BPD was 1.8\% among those with CFS, $0.4 \%$ among those with fatigue who did not meet criteria for CFS and $0 \%$ among those identified as well. ${ }^{26}$ The Kempke et al study published in 2012 assessed the prevalence of DSM-IV personality disorders among female patients with CFS, compared with 'normal community individuals' and 'psychiatric patient' controls. ${ }^{27}$ The prevalence of BPD was found to be $6.5 \%$ in patients with CFS, $6.5 \%$ in the community control group and $39.1 \%$ in the psychiatric patient control group. ${ }^{27}$ The 2015 study by Carvo et al assessed the prevalence of personality disorders among patients with CFS and found that $3.03 \%$ of the participants had a comorbid BPD diagnosis. ${ }^{28}$

\section{Discussion}

In psychiatric clinical settings, comorbidity of BPD with fibromyalgia or CFS is observed. As there has not previously been a systematic review of the literature assessing the prevalence of BPD in patients with fibromyalgia or CFS, or the prevalence of fibromyalgia and CFS in patients with BPD, this study represents an important step to further our understanding of possible relationships between these conditions. It would be important to study the association considering the prognostic implications and potential treatment challenges inherent in these complex conditions. The study also presents an opportunity to identify potential gaps in evidence regarding these complicated disorders.

\section{Fibromyalgia and CFS in patients with BPD}

We did not identify any studies that specifically assessed the prevalence of fibromyalgia or CFS in patients with BPD. However, as a facet of their longitudinal study published in 2004, Frankenburg \& Zanarini assessed the prevalence of "poorly understood medical syndromes' - an umbrella term encompassing CFS, fibromyalgia and temporomandibular joint syndrome - in patients previously diagnosed with BPD. ${ }^{10}$ The medical syndromes were diagnosed on the basis of the Medical History and Services Utilization Interview (MHSUI). Among patients who did not remit from BPD, the prevalence of a poorly understood medical syndrome was $42.2 \% .{ }^{10}$ Among patients who had remitted from BPD, the prevalence of a poorly understood medical syndrome was $25.0 \%$, suggesting that there is a high prevalence of these complex syndromes not only in patients with BPD but also in patients who have remitted from BPD. ${ }^{10}$ Clearly, further study is needed to assess the prevalence of these specific syndromes in patients with BPD and in patients who have remitted from BPD.

\section{BPD in patients with fibromyalgia}

A small number of studies have assessed the prevalence of BPD among patients with fibromyalgia. All three studies reviewed in this

\begin{tabular}{|c|c|c|c|c|c|c|c|c|}
\hline Authors & $\begin{array}{l}\text { Country } \\
\text { of study }\end{array}$ & $\begin{array}{c}\text { Year } \\
\text { published }\end{array}$ & $\begin{array}{l}\text { Participants } \\
\text { with CFS (n) }\end{array}$ & $\begin{array}{c}\text { Study } \\
\text { setting/design }\end{array}$ & $\begin{array}{l}\text { Diagnostic } \\
\text { criteria }\end{array}$ & $\begin{array}{c}\text { Gender } \\
\text { distribution }\end{array}$ & Age & $\begin{array}{l}\text { Prevalence } \\
\text { of BPD (\%) }\end{array}$ \\
\hline Johnson et $a l^{24}$ & USA & 1996 & 35 & Out-patient/case-control & $\begin{array}{l}\text { CDC-CFS* } \\
\text { PDQ-R }\end{array}$ & $88.6 \%$ female & $\begin{array}{c}34.8 \\
\text { (s.e.m.=1.3) }\end{array}$ & 17 \\
\hline Courjaret et $a 2^{25}$ & Belgium & 2009 & 50 & Out-patient/case-control & $\begin{array}{l}\text { CDC-CFS* } \\
\text { ADP-IV*** }\end{array}$ & $100 \%$ female & $\begin{array}{c}37.1 \\
(\text { s.d. }=7.9)\end{array}$ & 2 \\
\hline Nater et $a l^{26}$ & USA & 2010 & 113 & Community/survey & $\begin{array}{l}\text { CDC-CFS* } \\
\text { PDQ-4 }\end{array}$ & 81.4\% female & 44.3 & 1.8 \\
\hline Kempke et $a^{27}$ & Belgium & 2012 & 92 & Out-patient/case-control & $\begin{array}{l}\text { CDC-CFS* } \\
\text { ADP-IV** }\end{array}$ & $100 \%$ female & $\begin{array}{c}42.2 \\
\text { (s.d.=9.0) }\end{array}$ & 6.50 \\
\hline Calvo et $a^{28}$ & Spain & 2015 & 132 & Hospital/cross-sectional & $\begin{array}{l}\text { CDC-CFS* } \\
\text { PDQ-4 }\end{array}$ & 91.7\% female & $\begin{array}{l}47.7 \\
\text { (s.d.=9.1) }\end{array}$ & 3.03 \\
\hline
\end{tabular}


study were conducted in tertiary out-patient clinic settings, and the prevalence rates in these populations, therefore, may not be generalisable to a wider population. There was wide variation in the reported prevalences ( 1 to $16.7 \%$ ), and this variation may be partially explained by differences in geographical locations, demographic factors and study methodologies. Moreover, only the study by Uguz et al utilised a control group, and the difference in BPD prevalence between the fibromyalgia and control groups was not statistically significant. ${ }^{23}$ The patients in the Rose et al study had all been referred to consultation-liaison psychiatry, and this may have selected for higher prevalences of all psychiatric diagnoses, including BPD. ${ }^{22}$ Finally, all three studies focused on current prevalence, as opposed to lifetime prevalence, of BPD, thus diminishing the likelihood of capturing instances where individuals with fibromyalgia have a previous history of BPD and have since remitted. At present, there does not appear to be firm and consistent evidence to support the hypothesis that the prevalence of BPD would be higher in individuals with fibromyalgia compared with the general population.

\section{BPD in patients with CFS}

A small number of studies have assessed the prevalence of BPD in CFS, and the rates of BPD and CFS comorbidity reported in these studies varied widely $(1.8-17 \%)$. Again, this variability could be due to methodological, geographical and/or demographic differences across the studies. Of the three studies that compared the prevalence of BPD among patients with CFS with healthy controls, only one, the Johnson et al study, found a significantly higher rate of BPD among CFS sufferers $(17 \%$ v. $0 \%) .{ }^{24}$ Interestingly, the study by Courjaret et al found higher rates of BPD among healthy controls compared with individuals meeting criteria for $\mathrm{CFS}^{25}$ In all five studies reviewed, current prevalence, rather than lifetime prevalence, of BPD was assessed. Therefore, the studies may not have captured instances where CFS sufferers had previously met criteria for, and subsequently remitted from, BPD. There does not appear to be firm and consistent evidence to support the hypothesis that the prevalence of BPD is higher in individuals with CFS than in the general population.

\section{Limitations}

This study was limited by the fact that we confined the literature search to studies published in English or French. Selection bias would be another limitation of the study as studies published in peer-reviewed journals were included, and it was difficult to search for unpublished observational studies. We did not include welldefined, objective quality assessments of reviewed studies. However, considering the paucity of relevant research studies, we do not believe that this would have significantly altered the findings and conclusions in this study.

Even with the limitations described above, this study examined potential relationships between clinically relevant comorbidities through careful analysis of available research. It would be reasonable to conclude that, considering the marked heterogeneity of findings and the limited data available, there is a need for specifically designed community-based and longitudinal research projects with well-defined control groups to study potential associations between BPD, fibromyalgia and CFS. Chart reviews of patients diagnosed with one or more of the disorders may also provide further information while limiting selection bias. In future studies, it would be helpful to investigate lifetime prevalence in addition to point prevalence as this may elucidate any temporal relationships between the disorders.

A growing body of research is shedding light on the connections between early childhood adversity, mental illness and chronic physical health problems. ${ }^{29}$ Recent advances in neurosciences suggest that early life stressors induce persistent changes in neurocircuits which are implicated in the integration of emotional processing and regulation of arousal and vigilance. ${ }^{17}$ It is postulated that these changes result in increased reactivity to the environment, increased pain sensitivity, depression, anxiety and altered sleep patterns. ${ }^{17}$ It is not surprising, then, that all three disorders of interest are associated with early childhood adversity. It is possible, then, that the apparent patterns of comorbidity we encounter in clinical practice stem from common risk factors for all disorders of interest, rather than a specific relationship between any or all of the disorders.

Until more evidence is presented to either support or refute possible associations between the disorders of interest, the authors will continue to maintain an index of clinical suspicion for conditions such as fibromyalgia and CFS in patients with BPD as part of a thorough psychiatric assessment.

Sarah Penfold, MD, Department of Psychiatry, Queen's University, Kingston, Ontario Canada; Emily St. Denis, MSC, MD, Department of Psychiatry, Queen's University, Kingston, Ontario, Canada; Mir Nadeem Mazhar, FRCPsych, FRCPC, DABPN Department of Psychiatry, Queen's University, Kingston, Ontario, Canada

Correspondence: Mir Nadeem Mazhar, Department of Psychiatry, Queen's University, Kingston, Ontario, Canada. Email: mazharm@kgh.kari.net

First received 4 Feb 2016, final revision 2 Aug 2016, accepted 3 Aug 2016

\section{Acknowledgements}

The authors thank Lexi Ewing, Research Assistant with the Department of Psychiatry at Queen's University, for her help.

\section{References}

1 Lieb K, Zanarini MC, Schmahl C, Linehan M, Bohus M. Borderline personality disorder. Lancet 2004; 364: 453-6.

2 American Psychiatric Association. Diagnostic and Statistical Manual of Mental Disorders, 5th edn. APA, 2013

3 Swartz MS, Blazer D, George L, Winfield I. Estimating the prevalence of borderline personality disorder in the community. J Personal Disord 1990; 4: 257-72.

4 Widiger TA, Weissman MM. Epidemiology of borderline personality disorder. Hosp Comm Psychiatry 1991; 42: 1015-1021.

5 Bender DS, Dolan RT, Skodol AE, Sanislow CA, Dyck IR, McGlashan TH, et al. Treatment utilization by patients with personality disorders. Am J Psychiatry 2001; 158: $295-302$

6 Clauw DJ. Fibromyalgia: an overview. Am J Med 2009; 122: S3-S13.

7 Mease JP. Fibromyalgia syndrome: review of clinical presentation, pathogenesis, outcome measures, and treatment. J Rheumatol 2005; 75: 21

8 Jahan F, Nanii K, Qidwai W, Qasim R. Fibromyalgia syndrome: an overview of pathophysiology, diagnosis and management. Oman Med J 2012; 27: 192-5.

9 Fleming $\mathrm{KC}$, Volcheck MM. Central sensitization syndrome and the initial evaluation of a patient with fibromyalgia: a review. Rambam Maimonides Med J 2015; 6: e0020

10 Frankenburg FR, Zanarini MC. The association between borderline personality disorder and chronic medical illnesses, poor health-related lifestyle choices, and costly forms of health care utilization. J Clin Psychiatry 2004; 65: 1660-5.

11 Malin K, Littlejohn GO. Personality and fibromyalgia syndrome. Open Rheumatol 」 2012; 6: 273-85.

12 Macfarlane GJ, Thomas E, Papageorgiou AC, Schollum J, Croft PR, Silman AJ. The natural history of chronic pain in the community: a better prognosis than in the clinic? J Rheumatol 1996; 23: 1617-20.

13 Fukuda K, Straus SE, Hickie I. The chronic fatigue syndrome: a comprehensive approach to its definition and study. Ann Intern Med 1994; 121: 953-9.

14 Cho HJ, Skowera A, Cleare A, Wessely S. Chronic fatigue syndrome: an update focusing on phenomenology and pathophysiology. Curr Opin Psychiatry 2006; 19 $67-73$.

15 Afari N, Buchwald D. Chronic fatigue syndrome: a review. Am J Psychiatry 2003; 160: $221-36$ 
16 Saez-Francas N, Calvo N, Alegre J, Castro-Merrero J, Ramirez N, Hernadez-Vara J et al. Childhood trauma in chronic fatigue syndrome: focus on personality disorders and psychopathology. Compr Psychiatry 2015; 62: 13-9.

17 Heim C, Wagner D, Maloney E, Papanicolaou D, Solomon L, Jones J, et al. Early adverse experience and risk of chronic fatigue syndrome: results from population-based study. Arch Gen Psychiatry 2006; 63: 1258-66.

18 Lee S, Yu H, Wing Y, Chan C, Lee AM, Lee DTS, et al. Psychiatric morbidity and illness experience of primary care patients with chronic fatigue in Hong Kong. Am J Psychiatry 2000; 157: 380-4.

19 Davis MP, Khoshknabi D, Yue GH. Management of fatigue in cancer patients. Cur Pain Headache Rep 2006; 10: 260-9.

20 Sansone RA, Sansone LA. Fibromyalgia and borderline personality: theoretical perspectives. In Focus on Fibromyalgia Research (ed AP Rockne): 127-41. Nova science, 2007.

21 Thieme $\mathrm{K}$, Turk DC, Flor $\mathrm{H}$. Comorbid depression and anxiety in fibromyalgia syndrome: relationship to somatic and psychosocial variables. Psychosom Med 2004; 66: 837-844

22 Rose S, Cottencin O, Chouraki V, Wattier JM, Houvenagel E, Vallet B. Study on personality and psychiatric disorder in fibromyalgia. Presse Med 2009; 38: 695-700.

23 Uguz F, Cicek E, Salli A, Karahan AY, Albayrak I, Kaya N, et al. Axis I and axis I psychiatric disorders in patients with fibromyalgia. Gen Hosp Psychiatry 2010; 32 105-7.

24 Johnson SK, DeLuca J, Natelson BH. Personality dimensions in the chronic fatigue syndrome: a comparison with multiple sclerosis and depression. J Psychiatr Res 1996; 30: 9-20.

25 Courjaret J, Schotte CK, Wijnants H, Moorkens G, Cosyns P. Chronic fatigue syndrome and DSM-IV personality disorders. J Psychosom Res 2009; 66: 13-20.

26 Nater UM, Jones JF, Lin J-MS, Maloney E, Reeves WC, Heim C. Personality features and personality disorders in chronic fatigue syndrome: a population-based study. Psychother Psychosom 2010; 79: 312-318.

27 Kempke S, Van Den Eede F, Schotte $C$, Claes S, Van Wambeke $P$, Van Houdenhove $B$, et al. Prevalence of DSM-IV personality disorders in patients with chronic fatigue syndrome: a controlled study. Int I Behav Med 2013; 20: 219-28.

28 Calvo N, Saez-Francas N, Valero S, Alegre J, Casas M. Comorbid personality disorders in chronic fatigue syndrome patients: a marker of psychopathological severity. Actas Espanolas de Psiquiatria 2015; 43: 58-65.

29 Scott K, Von Korff M, Angermeyer MC, Beniet C, Bruffaerts R. Association of childhood adversities and early-onset mental disorders with adult-onset chronic physical conditions. Arch Gen Psychiatry 2011; 68: 838-44. 